\title{
Techno-Scientific Spectacle
}

The Rhetoric of IMAX in the

Contemporary Science Museum

J oanna Ploeger

Poroi, 3, 2, December, 2004

The crowd is buzzing, and not just because everyone's getting drunk. In the lobby of the Ontario Science Centre in Toronto, about 300 investor relations professionals are gorging themselves on wine, beer and hors d'oeuvres while anxiously wait to be allowed into the IMAX dome theatre for privately arranged screening of one of the most talked about movies of the year: Everest.

- Canadian Business

\section{Introduction}

1 Science education is soaring in creativity. From the classroom to the museum in the past decade, the drive to develop entertaining and interactive vehicles for "public understanding" of science has accelerated. Science museums once were suitable mainly for school field trips; now they are vacation attractions alongside zoos, malls, and cultural centers.

2 Many applaud the new marketing of science centers for attracting audiences to scientific venues, but some question the rhetorics and ideologies of entertainment. How does our sense of science change when we experience it as an "attraction?" What does it mean to consume science as "tourism?" How do ties of science to leisure and entertainment change public comprehension of scientific or technological practices? How do they shift relations among science, technology, and society? To address such issues is to explore how science communicates its knowledge and culture to larger publics. Thus science education can be a major topic for rhetoric of inquiry.

3 IMAX films in science centers are telling examples. Their recent centrality to museum experiences indicates the dominance of market-driven and entertainment-based ideologies in the design 
and administration of science education. The emerging model taps the cultural spectacle of the museum. This positions visitors as "science tourists" who buy tickets to be transported to distant and mysterious worlds of science. Yet one goal is to make science more familiar. Hence exhibitors continually redesign features to reflect current norms of entertainment. All this affects our public dialogue in societies that depend on advanced sciences and technologies.

4 To serve marketplace logics, centers can try to simplify complicated problems of science and experiences of technology, yet this undermines the stated goals of many museums. The trouble is that heavy reliance on IMAX to build patronage can produce spectators rather than participants. This reinforces the disposition of museums to keep people at a distance rather than engage publics as fully as possible. To attract audiences through IMAX and other spectacular technologies can be to isolate museums further from the communities that they seek to instruct.

5 The IMAX form of scientific spectacle is more than "smart marketing" through visual display and interactivity. To provide science as entertainment can be to promote a seductive yet distancing rhetoric for relations between science and society. It packages science as an object for the pleasure of paying audiences. It also encourages visitors to see science as a way to transform nature and culture into commodities. Viewer experiences constructed by IMAX serve scientific tourism.

6 To illustrate IMAX experiences and how they situate museum patrons as spectators, I analyze the rhetoric of sights and stories in Yellowstone (1994). I specify its potential impact on audience conceptions of the roles for science and technology in preserving public lands. Then I explain in more general terms how the current positioning of IMAX films in science museums can keep visitors and administrators from recognizing more complex and meaningful relations of science to society.

7 Rhetoric of inquiry plays a key role in the argument. To position the science museum as an attraction is to undo cultural uses of museums as spaces for education, particularly of young people. Rhetorical analysis of inquiry as experienced by IMAX viewers can help show how the format undermines pedagogy for science and technology. Of late, the ideological underpinnings of museums as places for social interaction and knowledge production have come into question. Uncritical celebration of IMAX steps back from 
many urgent, if difficult, issues about the functions of museums in our society. For science museums especially, where categorizing and re-presenting the world are prominent experiences for curators and patrons alike, these issues are vital to engage. Rhetorical analysis can speak to the larger cultural discourses activated by our IMAX experiences for museums, individuals, and their communities.

\section{Experiencing the Science Museum}

8 Building museums around the desires of touring patrons is nothing new. ${ }^{1}$ The purpose of this essay, therefore, is not to restate that our experiences of museums can be shaped by spectacular rhetorics grounded in logics of the marketplace. Instead the aim is to analyze a specific experience in one type of museum for its ideological impact on visitors. More pragmatic than theoretical, this critique of experience in the IMAX theaters provided by science museums considers not only how they function currently but also what they might become.

9 Trips to science museums provide a variety of experiences. Some prompt us to think about the practices of science by detailing processes of research or dynamics of scientific understanding. Others celebrate relations between science and technology. Some "stick to the basics" by teaching fundamental concepts in biology, physics, chemistry, and other scientific disciplines. Many draw attention to "the world out there" and myriad applications of scientific knowledge. Others pull us into the inner worlds of science and its practitioners. Along the way, commonly understood categories of "scientific" knowledge are defined, exploded, and redefined. Boundaries are drawn, erased, and reinstated. The science museum is an ambiguous space. In a world that too often purports to be about facts, laws, boundaries, and clearly defined ideas, the science museum often can (and should) prompt more questions than it answers.

10 The "science" that fills such museums is equally ambiguous. Some argue that the more open the museum - the more definitions of "science" it constructs or tolerates - the greater the service to patrons. Yet openness and engagement are difficult to define in practical terms and even harder to manifest within a particular institution that needs to build and sustain patronage. While society has expanded the horizons of science, many museums still struggle to prepare visitors to process the varied experiences of 
science that define contemporary life.

11 My own experiences confirm a general trend toward "interactivity" that allows museum patrons to engage exhibits in personal terms. Many museums have replaced panel upon panel of textual explanation with illustrations, visual analogies, and participatory exhibits. Such displays often clarify difficult concepts and make abstract content more approachable for audiences who lack technical training. But the interactivity is, at best, partially understood. Thus these changes in museum culture raise important new questions. What are the origins and consequences of the shift to more visually stimulating environments?

Proponents suggest that the greater the involvement, the greater the likelihood of learning. Yet such claims address only the quantity of interaction. What of its quality and experience? How might active engagement yield to passive spectacle? Where are boundaries between education and entertainment?

\section{Education, Public Understanding, and Current Museums}

12 Science education for citizens and entertainment culture for consumers both influence what science museums can be.

Museums long have been considered places to educate the public particularly young children - about science and its role in society. Hence many defend science museums as capable of making key contributions to public understanding of science. Even those who advocate a pedagogical approach are aware, however, that science museums compete for visitors with institutions that offer highly entertaining fare. They acknowledge that education can only proceed where there are students, and they reason that science museums must find new ways to woo potential visitors.

13 But some scholars who criticize the museum as an instrument of "public understanding" question whether visitors to science museums come to be "educated" in the sense of acquiring facts or theories. Rennie and Williams argue for treating science centers as spaces where people make sense of science and construct personal relationships to it. Criticizing long-held definitions of "scientific literacy," they ask, "What do science centers communicate about the nature of science and the scientific enterprise? What relationship between science and society do they portray?" (2002, p. 266). Henriksen and Froyland test science centers as places for dialogue and civic interaction by examining 
how patrons use them as resources for assessing radon hazards. "If museums are to function as dialogue institutions and service institutions," the two contend, "Forms of communication in which the audience has a more active role, such as lectures, discussions, and workshops, might be more suitable" than passive, entertainment oriented exhibits (2000, p. 410).

14 These scholars pose interesting issues about the pragmatic, civic, and cultural potentials of science museums. Yet they do not challenge the rhetorics that shape knowledge production, "education," or "engagement" in the museums. These scholars clearly value science museums for their pedagogical contributions, actual and potential. Still they rarely question the education that science centers might produce. Attention to "scientific literacy" and "public understanding" focuses on gaps between pedagogical intentions and outcomes of various exhibition strategies, but it also often elides troubling questions about the "marketing" of museums as attractions.

15 IMAX has become the central pillar of marketing strategy for many museums. IMAX is supposed to help museums compete for patrons, but how? Is it to educate? To entertain? Is it mainly for imparting scientific facts? Is it mostly to engage citizens in learning about the role of science in society? Is it more for drawing citizens to the larger facility or even for funding other exhibits? To learn how might IMAX serve these and other ends, we should analyze how people experience it.

\section{IMAX and the Marketing of the Science Museum as a "Destination Attraction"}

16 To consider how visitors experience science museums is crucial for understanding their rhetorical dimensions. If we examine museums in relationship to the rest of culture, new and sometimes troubling perspectives emerge from current marketing strategies. Perhaps the most notable symptom is the growing sense of the museum as a "destination." An increasing number of science museums large and small have added IMAX theaters in hopes of enhancing attendance and "adding value" to museum experiences. They often encourage patrons to build visits around feature films. A typical visit might begin by exploring several permanent or special exhibits, but it frequently culminates in a trip to the IMAX theater. More often than not, museums offer special "combined" 
admission tickets to encourage patrons to explore both the museum exhibits and the films.

17 To many science educators and museum administrators, IMAX seems to represent the ultimate, immersive experience of science. IMAX films have also been sold as a bridge between science as depicted in the museum and science in the larger, "real" world. IMAX has been marketed to museums and patrons as a vehicle to transport visitors to worlds beyond museums.

18 But there is little evidence that IMAX fulfills such promises. IMAX might be an "immersive" technology, yet "immersive" need not mean "interactive." It can be argued that IMAX is a passive experience for most viewers. Some report that a principal attraction is "letting go" to allow the technology to structure the experience. IMAX pleasures often are similar to thrill rides: loss of control, disengagement from ordinary sensation, and "total immersion." This casts IMAX as a descendant of motion simulators and other forms of film-based entertainment more than a revolution in interactive science education (Holstrom 1996). Rethinking visitor experiences of IMAX might give museum administrators new insights into the technology's capacities to encourage engagement with science.

19 The ideological content of most IMAX features presents further cause for concern. IMAX films do not escape perils of product placement and sponsorship. In many instances, the films become full-length exercises in product placement. Everest, a recent IMAX hit, was sponsored by Polartec. IMAX museum productions underwritten by Lockheed-Martin for conventional, military, and space-flight technology have become long-running favorites. ${ }^{2}$ The increasing popularity of IMAX seems to fuel commercial influence.

20 The commercial development of IMAX has two trajectories. IMAX continues to expand into mainstream markets and develop noneducational features. An example is the IMAX version of Matrix Revolutions, designed for science-center theaters as well as commercial IMAX theaters. The museum market remains uniquely positioned, however, as companies like Destination Cinema team with National Geographic and Disney to secure their hold on the museum and attraction market. As IMAX struggles to break into the mainstream film market, it draws on it origins in the museum complex: "They were the Discovery Channel of the large screen format and took us to exotic places. Competition for the large screen format is burgeoning now, and if IMAX remembers to 
continue taking people where they can't go, [it] will continue to be popular" (Holstrom 1996).

21 Close examination of the influence of the institutions and technologies of commercial production points to the most troubling ideological dimensions of the IMAX experience: the spectacle of techno-scientific tourism. IMAX films routinely traffic in a neo-colonial discourse of "the other" that exoticizes people and places for purposes of entertainment and consumption. These portrayals are, in many ways, the technological outgrowth of colonial discourses endemic to much of museum culture. IMAX films often recall early colonial imagery of "the exotic" as they create spectacular displays of native culture for consumption by largely white and privileged audiences. ${ }^{3}$ When IMAX technology becomes the central "attraction" for a supposedly educational experience, such rhetoric is particularly disturbing. This peculiar combination of marketing and educational philosophy aggravates the colonizing imagery of the museum within the discourse of science education.

22 Arguably well-intentioned museum administrators are sold on the idea of large format, particularly IMAX, films as a way to usher in a new era in science education. Yet the uncritical adoption of IMAX technology contributes to the resurgence of a deeply conservative discourse that often works against change. The brand of engagement that many science educators seek - a dialogue that encourages non-scientists to participate in public dialogue about science, technology, and culture - is simply not realized in the existing narratival and technological experiences of IMAX. IMAX is a step away from, not toward, educational change for science museums. The question is not if IMAX produces knowledge, but what kind of knowledge it produces.

\section{A Techno-Scientific Tourist in the Land of the Yellow Stone}

23 Techno-scientific tourism results from a multi-layered process that commodifies science and its objects as forms of spectacular entertainment. Producers market cinematic interpretations of science as education to museums, which sell a scientific experience to consumers as entertainment. What are the consequences of this alliance for how IMAX films depict science how IMAX viewers experience it?

24 At best, as this section explains, the depiction of science in IMAX 
film is conservative. At worst, it is deeply troubling. Perhaps because of the long association between large-format cinema, tourism, and the production of "attractions," most IMAX films depict science and technology as means to conquer and control nature for human use. Framed by narratives of "progress" and heavily laden with discourses of "exploration," many Imax features offer viewers scientism rather than science. They can undermine recent efforts by science centers to present the nuances of science as complicated practices rather than celebrated products or achievements.

25 Films of natural history form the largest category of Imax features. They provide many egregious examples of scientism and its close relationship to the ideologies of colonialism that transform natural systems and native cultures into objects for control by science. These films position viewers as passive voyeurs of worlds constructed through science. In doing so, they promote interpretations of science that run counter to evolving principles of science literacy. 4 To specify how this process unfolds through narratival, visual, and experiential features of IMAX, a rhetorical analysis of Yellowstone is helpful.

\section{Plot Structure}

26 Yellowstone chronicles the evolution of both historical and scientific understandings of Yellowstone National Park. It reframes the history of human relations to nature through a colonizing narrative that interweaves a myth of western exploration with Native American and scientific interpretations of nature. Specifically it displays humans as "acting upon" the wilderness, so that the history of Yellowstone becomes one of increasingly invasive and technological encounters with the land and its inhabitants. Thus the film reinforces the dominant western scientific understanding of nature as something to be controlled through human action. The Yellowstone parklands manifest preservation through human control.

27 The "ancient story" of the park unfolds in stages of human interaction with wilderness. It begins with Native American culture, moves through the "trapping and trading" period in western territories, and culminates in the preservation and scientific exploration of the area as a national park. This linear history gives meaning to tourist experiences as validations of "progress," defined as a shift from native ways of knowing toward seemingly more complex and objectified understandings of the 
world.

28 The narratival and visual framework of the film comes from exploration myths of the American "frontier" and of western science. These reinforce the film's linear interpretation of progress. Nature is something to be conquered and controlled through actions of the "explorer." In image, character, and conduct, the "explorer" mediates between human being and nature. Yellowstone traffics in the cultural identity of Native Americans in order to articulate the qualities of the explorer. The film represents Native American relations with the land as inferior to western, scientific forms of land management.

29 The film begins by equivocating western and Native American attitudes (and actions) toward nature. Early scenes show explorers interacting with the native culture, and they accord similar attention to the contrasting perspectives on relations between humans and nature. The rest of the film, however, subordinates Native American relations to the more powerful scientific relations. Its explorers display an increasing mastery over nature facilitated in large part by their reliance upon technology and scientific method.

30 The transition of power from native to explorer is further evident in the gradual elimination of both native views and images of native culture as the film progresses. This suggests that native understanding is simply one early link in the chain of intellectual progress - a primitive precursor to scientific knowledge. While images of native culture play a significant role in early portions of the film, it accords native knowledge thematic importance only as a marker for the superior scope and power of scientific understanding. The narrative construction of the western explorer clarifies its portrait of native culture.

\section{Thematic Links -}

\section{Redefining the Western Explorer}

31 The western explorer initially appears as J ohn Coulter, living in the 1800s style of the trapper-trader. Coulter explores the "land of the Yellow Stone" by developing relationships with the land and its native people. Similar to the Native Americans, the trapper-trader exhibits a symbiotic relationship with nature. We see Coulter traveling the wilderness alone, living "off the land" and having only cordial encounters with a homogenized native culture. 
32 The film also manifests its transformation of relations between explorers and natives through a doubly marked forest ranger of Native American descent. She speaks of a Native American love of the land and her cultural understanding of harmony with nature as the images link her to the world of the western explorer. Wearing a park service uniform, she tenderly brushes dirt from a stone inscribed by J ohn Coulter to mark his journey in 1806. While the narration emphasizes her Native American heritage, the images remind us that, as a park ranger, she is also a descendent of Coulter. She becomes a verbal and visual link between these two otherwise disparate practices that relate humans to nature. A scientifically trained park ranger, she has supplanted her ancestors as the "guardian of mother earth." Her "progression" to the status of ranger and scientist suggests that Native American perspectives can be easily contained within scientific understanding. She implies that science is the natural, inevitable successor to the native way of life.

33 The first two thirds of Yellowstone connect western and Native American conceptions of nature, then the last third links the western explorer to the modern scientist. It begins with the graduate student who first explained Yellowstone's geysers as volcanic action. Like the western explorer, the student investigates an unknown area. He risks personal danger to increase his understanding, and ultimately his control, of nature. In one particularly gendered scene, the male graduate student pursues scientific "exploration," while his female companion prefers "field trips."

34 The film portrays the student's discoveries as the foundation for modern, scientific explorations of Yellowstone's geo-thermal activity. Like trapper-traders, scientists recognize that there is something to be gained from interaction with the land. Early exploration results in the discovery of valuable resources; current science generates the discovery of valuable knowledge. In both, recognition of the productive capability of the land forms the foundation for new, non-native understandings of relations between humans and nature. The film presents Yellowstone as "preserved" to sustain human life but also to provide materials, experience, and knowledge not attainable elsewhere.

35 This emphasis on the practical potential of the land greatly complicates the function and justification of preservation. It implies that progress by early explorers and their scientist successors links somehow to a utilitarian ideology of preservation. 
The narrative suggests that "progressive" people recognize and exploit efficiently the resources of the land and its people. The interpenetration of utility, preservation, and progress appears in a second major figure that organizes the film: a spatial pattern of development as humans increasingly entering and controlling nature.

\section{Spatial Organization - Degrees of "Acting Upon" the Land}

36 Human action in nature begins for the film with fictive images of Native American culture. The structure of action corresponds to the temporal and conceptual themes in the film's narrative. The film shows Native Americans living in harmony with nature but ignorant of the land's vast utility. One early scene depicts a Native American backing away from a bear. Appeasing the angry animal seems to suggest that Native Americans seek balance with nature or accept dominance by the land.

37 Not surprisingly, the film's trapper-traders feature increasing dominance of nature by humans. The trapper-traders employ more and more invasive methods of "acting upon" the land, and the film treats this exploration as a linear accumulation of knowledge. J ohn Coulter first "explores" by venturing on foot beyond the area inhabited by Native Americans. Later trappertraders traverse the vast territory by horseback or raft, and make camps as they travel. New methods of travel mark increased ability to tame the wilderness and tap its resources. Encampments signal development of a permanent human presence in the "land of the yellow stone." The angry bear returns, only this time the explorers hold their ground, signifying an increased willingness to command nature.

38 The preservation of Yellowstone as a national park becomes the film's turning point in our spatial sense of the relationship between humans and nature. Earlier exploration has been characterized by surveying and mapping the area then imposing boundaries on the wilderness. The nature of exploration widens during a scene in which a survey party argues over the ultimate disposition of the land. Eventually one member declares that the land should be preserved for all people. "Preservation" becomes a specific, powerful way of "acting upon" the land, expressing the human control of nature.

39 This challenges the character of Yellowstone as a living system that 
spills over, even defies, boundaries. "Preservation" articulates a new meaning of the land and its inhabitants as specimens to be valued for their potential knowledge and resources. Delimiting, marking, and naming Yellowstone as an object of analysis distinct from the cultures that inhabit and use of it, explorers from trapper-traders to scientists are poised to transform and eventually replace the Native American relationship to nature. The film's narrative nods to the Native American spirituality in opening scenes that depict the aboriginal culture's relationship with "the great bear." Yet the film paradoxically argues that this can be reproduced through a scientifically driven form of preservation that irrevocably alters the native ideology of balance between human beings and the natural world.

40 The graduate-student narrative illustrates this paradox. Both the native and the explorer need to understand nature, but they are motivated by different senses of the land. The native values Yellowstone for sustaining human life; the scientist analyzes the area for its unusual properties. The film depicts Native Americans as managing the land through experiential and intuitive understanding. Yet the film displays scientists as seeking much greater control over the environment. The film shows repeatedly that this can be achieved only through exploration that reaches under the surface of the land. The gradual progression from manipulating the surface structure to examining the substructure of the park signals less an equivalent or alternative sense of the land than an entirely new level of control for humanity over nature.

41 The film also emphasizes how technology facilitates human presence in the wilderness and control over it. The narrative marks progress in part by the levels of technological prowess displayed by the various "explorers." Early in the film, J ohn Coulter uses snowshoes to traverse the vast territory, a technology that equals the native culture or advances it slightly by Western standards. Yellowstone soon shows early survey teams using large rafts to travel deeper into the wilderness to employ various tools to measure and map the area. By late in the film, the use of modern scientific equipment to study geo-thermal activity becomes a pinnacle of human dominion over nature. Successive explorers use technology to expand the territory under human control.

42 For the earliest explorers, technology facilitates travel to previously unexplored areas. The surveyors and scientists further expand the Yellowstone territory through magnification, remote 
sensing, and other means that bring the previously inaccessible within reach. IMAX works much the same way for viewers. Its technology enhances the senses of viewers so that they can experience vicariously the world of the scientist-explorer.

43 To frame viewer experiences through technological enhancements emphasizes invasive control. The film highlights the technologies used to conduct scientific research at Yellowstone. In one scene, a researcher explains the underlying structure that produces geysers while data from global-positioning satellites inform computer simulations that take viewers below the park's surface to see the origins of this geological activity. Thus the film suggests that the technologies which enable us to see beyond the usual limits on human sight - technologies developed and deployed exclusively by science - enhance human relations with Yellowstone.

44 Technology also expands the visual field in a second experiment detailed by the film. In this sequence, a video camera lowered into the mouth of Old Faithful records activity deep in the geyser prior to its eruption. Viewers see only a black and white picture of bubbles, but the film still implies the manipulation of nature through technology. Having "experienced" native perspectives early in the film, viewers can see in this later scene the power of a scientific gaze. The image itself is barely comprehensible to audience members, yet it illustrates the access made possible by applying scientific relations between humans and the land. The earliest sequences in the film emphasize limits, but these geyser scenes celebrate a human transcendence of physical and intellectual boundaries through technological devices.

45 The featured instruments do not seem to overpower nature. Instead they produce information about how, why, and when geysers are likely to erupt. The film implies that the power to recognize, explain, and control complex natural events makes the technologically enhanced understanding of scientists superior to the intuitive, experiential understanding of natives. The same sequences also reinforce the related separation between self and other by claiming that the inner workings of the earth are better understood through scientific technology than spirituality. As the film draws to a close, these and other examples of technologically driven research imply that human interaction with nature is most effective, most utilitarian, when controlled by advanced technologies.

46 Although the film celebrates scientific control and preservation as 
the means for western explorers to extend and eventually supplant Native American relations to nature, the film never makes available to viewers the scientific understanding that drives this transition. In several scenes, the audience "sees" what the scientists see but receives little explanation of the images. The film features invasive technologies of research, and it implies that science conveys the power to control nature, but it never explains how. Furthermore the film leaves out bad consequences that might result from attempts to manage the land though technology. In reality, the human intervention to preserve Yellowstone has been quite disruptive - producing roads, trash, disruption of habitats, and violent encounters with animals. Viewers of Yellowstone see none of this. The land depicted in the film is always perfectly controlled: preserved yet somehow improved through the efforts of science.

47 By obscuring the details of scientific intervention in the wilderness, the visual and verbal narratives of Yellowstone subvert the potential for public dialogue about controversies that arise from the maintenance of public lands. Moreover the film's depiction of science as an extension of the western frontier mythologizes rather than illuminates the actual practice of science. Thus the popular appeal of Yellowstone and similar IMAX films may reside in their use science and technology to extend longstanding myths of western culture. Nothing in Yellowstone challenges viewers to consider how the production of scientific knowledge unfolds within an ideology that frames human relations to the land.

\section{IMAX Technology and Rhetorical Impact: The Total(izing) Experience of the World and its People}

48 IMAX technologies contribute significantly to the film's rhetorical power. The huge, curved, almost enveloping screens for IMAX immerse viewers in visual spectacles that exceed ordinary cinema. The IMAX hemisphere of surrounding, permeating sound produces auditory equivalents. Before each feature film, science centers typically introduce IMAX viewers to these imposing technologies as spectacles in their own right. They directly reinforce the message of a movie like Yellowstone.

49 The popularity of IMAX results in large part from providing viewers with sights and sounds that mimic or even outstrip exotic 
realities. Yellowstone enables viewers to experience the grandeur of the park from a variety of perspectives inaccessible to the ordinary tourist. It suspends viewers into a developing "picture postcard" of the park. For an hour, the film bombards the audience with visual and auditory stimuli that underscore the power made possible through science.

50 Yellowstone makes full use of IMAX capabilities, offering viewers a wide range of natural and human perspectives on the park. Within a single scene, viewers can experience (in rapid succession) a bird's-eye view from high above the wilderness, a native's "earthbound" perspective on the forest, and an explorer's encounter with the unknown. Early in the film, for example, the audience sees a bear cub from the perspective of a Native American child. As Yellowstone proceeds, viewers gaze upon the landscape through the eyes of explorers both distant and recent. In one particularly complicated sequence, the audience retraces the steps of an early explorer as native guides introduce him to the territory. Viewers first see the forest from the perspective of a native but soon soar over the wilderness like a bird on the wing. When they glide past a break in the treeline, though, they plummet earthward to peer over a large waterfall as seen by an awestruck explorer.

51 Other elements reinforce this enhanced, extra-human sense of Yellowstone. The size of IMAX film, enhanced by "IMAX-specific" filming techniques, can provide as yet unrivaled depth and breadth to images of the control made possible by science. Ironically the power of IMAX emerges from its capacity to encourage viewers to surrender control of what they see and hear. Often IMAX taps the physiological response resulting from spatial disorientation more than narratival content to alert viewers to the power of the scientific gaze. IMAX can fuse this virtual vertigo with oscillation between the desire for control and the threat of losing it to present science and technology as necessary mediators between humanity and nature.

52 The disquieting and yet pleasurable experiences of audiences become a metaphor for the human-nature relations narrated by Yellowstone. Its use of an explorer's gaze eases audience acceptance of Yellowstone as the manifestation of a productive relationship between human beings and nature. As "explorers," viewers become voyeurs. At a close but safe and inactive distance, they observe the land and the people who encounter it. In many ways, this exchange of power, knowledge, and experience mirrors 
that of conventional tourism at Yellowstone. IMAX viewers pay to experience the park from an explorer's perspective in much the same way that conventional tourists pay entrance fees to support the scientific management of the land for public use. Yet magnification, computer simulation, remote sensing, and aerial photography provide IMAX viewers further opportunities to explore from a position of safety. IMAX experiences require no actual engagement with the natural world. The spectacular array of technologically produced images does little to bring audiences closer to nature and, instead, serves to reinforce the separation between humans and nature.

53 This shift away from actual engagement with nature toward mediated experiences of the parkland might be seen by some as a solution to the destructive crush of tourism at Yellowstone. Yet the film's colonial structure perpetuates many of the values that produce such problematic relations between humans and nature. The film's words and images conspire to create an ethic of control that is incompatible with alternative (non-human centered) models of preservation. The history and future of Yellowstone may be the film's subject; but the viewers experience technology and science, not nature. The film even nudges viewers to recognize their experiences as scientific, because it both mimics and portrays the world as seen through tools of the scientist-explorer. The technology provides viewers a series of increasingly invasive perspectives on the park. These condition viewers visually to accept as somehow natural the voyeuristic character of a technoscientific gaze. Particularly as magnified by IMAX technologies, the film's visual interpretation of the scientific gaze encourages viewers to survey the "domain" now under their control. It strongly reinforces an argument that human colonization of nature is necessary and desirable.

\section{Conclusion}

54 To accept the IMAX interpretation of Yellowstone is to accept a techno-scientific relationship with the world around us. The film argues that nature neither dominates nor coexists with us. Instead nature is something for us to control - in this case through scientific exploration and preservation. Humans have the right and ability to determine the development of nature. To show this, the film appropriates then eradicates the primary antithesis: a Native American sense of the relations between humans and nature. Consistent with the ideology of progress, the film defines 
human relations to the land instrumentally. Even as it is "preserved," the land exists for the use and benefit of humans.

55 By continuing to emphasize the "uses" of the park, Yellowstone produces a contradictory understanding of preservation that fails to confront pressing issues about managing natural areas for human benefit. The film predicates our acts of preservation upon human needs: humans preserve Yellowstone so that it can be a resources for scientific study and human enjoyment. The film focuses on the benefits that can be gained from intervention in the parklands, not on what humanity might contribute to the area.

56 Such self-centered preservation invariably denies the complicated, inevitable impact of human intervention in the area. It oversimplifies relations between human and nature. If carried out, it puts the fundamental integrity of the natural system at risk. In practical terms, the narrative of preservation presented in Yellowstone ignores several contradictions that can arise out of the proposed uses for the park. For example, resource management, scientific study, and large-scale tourism often work at crosspurposes. Tourists and scientists might seek a pristine environment, but rarely can they experience it together. Tourists often disrupt the area scientists seek to study, and scientific activity can spoil the tourist illusion of an uncomplicated wilderness. Similar quandaries arise for allocating the park's resources. Are grasslands to be reserved for the wildlife indigenous to a park, or should pubic grazing be permitted?

57 Close examination of Yellowstone suggests that these and other controversies over public lands trace in part to a colonial articulation of "preservation." This continues to be legitimated by an association with science and perpetuated by viewer experiences of popular media such as IMAX. The verbal and visual devices of Yellowstone that position viewers as "explorers" detail this understanding of preservation, and they obscure other perspectives on human responsibility to nature. The spectacle of IMAX imagery drives this transformation of viewer experience. The film invites, even urges, viewers to survey the territory and cultures set before them in much the same way as do its scientists and explorers. The capacity of IMAX to simulate "being there" situates theater spectators in the role of explorers so that they may experience "progress" from inside the boundaries of the film's utilitarian, colonial narrative.

58 The enveloping, "insider" experience of IMAX should generate 
concern about the use of these films for educational purposes. Most often marketed as science education, IMAX films more closely resemble mainstream entertainment. Driven by market forces to fulfill the latest expectations of entertainment, IMAX productions emphasize spectacle at the expense of engagement. These films work first to satisfy public demand by enacting themes of power and control for audiences raised on a steady diet of action pictures. Scientific colonialism, with its underlying argument for intellectual and cultural mastery, provides a convenient narrative for experiences that excite viewers.

59 Excitement and engagement are not anathema to education. Still we do well to notice how monetary concerns drive the production and consumption of IMAX films. Themes of control do little to clarify complicated environmental and cultural issues, and they do even less to promote public understanding of science. But they do sell tickets. Yellowstone reverts to established, dominant interpretations of relations between humans and nature. This reflects the degree to which its production was shaped by material rather than educational concerns. Audience response seems to confirm the entertainment value of techno-scientific tourism. Yet the tendency of IMAX films to oversimplify the relations among humans, science, and nature raise troubling questions about their use for education.

(C) J oanna Ploeger, 2004.

\section{Notes}

1 A particularly useful introduction to critical analysis of the modern museum is Tony Bennett's The Birth of the Museum (1995) . Cultural criticism and post-colonial studies by Bennett and others detail visitor experiences of museums and direct our attention to the commodification of people as objects of tourism, often in the name of science. Work in museum studies also provides valuable insights into both the educational and marketing ideologies operative in contemporary museums. For detailed discussions see Roberts (1997), Hein (1998), Kotler (1998), Dierking (2000, 2002), and Weil (2002).

2 For discussion of corporate sponsorship of IMAX films, see the articles referenced below for Aviation Week and Space Technology, Canadian Business, and People. 
3 The rich scholarship on images and museums in colonialism shows how scientific discourse can objectify individuals and cultures. By making them "objects of scientific study," often through photographs and films, museums have supported colonial power. IMAX extends colonizing discourse, but it extends discourses of science and scientism in other ways as well.

4 "Scientific literacy" is a long-contested term. Once defined as comprehension and recall of scientific facts, it has become for neoliberals (a measure of) the capacity to participate in democracies advanced in science and technology. Among those who champion a more liberal notion of scientific literacy, concerns about the potential limitations of "entertaining" museum spaces are not new (Champagne 1975). Despite the criticisms, museums continue to adopt IMAX in the name of interactive education.

\section{References}

Borchelt, R. 2001. "Communicating the Future: Report of the Roadmap Panel for Public Communication of Science and Technology in the Twenty-First Century." Science Communication, 23, pp. 194-211.

Barker, F., P. Hulme, and Margaret Iversen, eds. 1994. Colonial Discourse/ Post Colonial Theory. New York: Monthly Review.

Bennett, T. 1995. The Birth of the Museum: History, Theory, Politics. London: Routledge.

Merrill, K. (director). 1994. Yellowstone [Motion Picture]. United States: Destination Cinema (producer).

Dierking, L. D., and J . H. Falk. 2000. Learning from Museums: Visitor Experiences and the Making of Meaning. Lanham: Rowman and Littlefield.

Dierking, L. D., and J . H. Falk. 2002. Lessons without Limits: How Free Choice Learning Is Transforming Education. Lanham: Rowman and Littlefield.

Danilov, V. 1983. “IMAX/Omnimax: Fad or Trend?” Museum News, 65, pp. 34-44. 
Foucault, M. 1995. Discipline and Punish: The Birth of the Prison, A. Sheridan, tr. New York: Random House, (1975), 2d ed.

Gold, R. 1985. “IMAX Eyes History.” American Cinematographer, 66, pp. 58-64.

Gregory, J ., and S. Miller. 2000. Science in Public: Communication, Culture, and Credibility. Cambridge: Perseus.

Hein, George E. 1998. Learning in the Museum. London: Routledge.

Henriksen, E. K., and M. Froyland. 2000. "The Contribution of Museums to Scientific Literacy: Views from Audience and Museum Professionals." Public Understanding of Science, 9, pp. 393-415.

Heuring, D. 1990. "IMAX Presses to the Limit." American Cinematographer, 71, pp. 34-44.

Hirst, N. 1992. "IMAX Finally Gets the Picture.” Canadian Business, 65, 1, pp. 56-60.

Holstrom, D. 1996. "Popcorn, Candy, and 3-D Glasses Coming to a Mall Near You." Christian Science Monitor, 88,173, August 8, p. 10.

Kehoe, L. 1994. "Ex-IBM Chief to Head Canadian Films Group." Financial Times, September 15, p. 27.

Kotler, Neil, and Philip Kotler. 1998. Museum Strategy and Marketing: Designing, Missions, Building, Audiences, Generating Revenue and Resources. San Francisco: J ossey-Bass.

Logan, R. 2001. "Science Mass Communication: Its Conceptual History." Science Communication, 23, pp. 135-163.

Magid, R. 1993. “Gorillas in Their Midst: An IMAX Team’s Adventure." American Cinematographer, 74, pp. 38-42.

Morgensern, J. 1994. "IMAX in the Rain Forest." Wall Street J ournal, February 24, p. A12. 
Rennie, L. J., and G. F. Williams. 2002. "Science Centers and Scientific Literacy: Promoting a Relationship with Science." Science Education, 86, 5, pp. 706-727.

Roberts, Lisa. 1997. From Knowledge to Narrative: Educators and the Changing Museum. Washington, DC: Smithsonian Institute Press.

Rajan, G., and R. Monhamram, eds. 1995. Postcolonial Discourse and Changing Cultural Contexts. Westport, CT: Greenwood Press.

Sharp, D. 1989. "The New Cinema.” Riba J ournal, 96, pp. 52-55.

Sherrill, N. 1983. "Behold Hawaii." American Cinematographer, 64, pp. 62-66.

Sorrell, T. 1991. Scientism. London: Routledge.

Symonds, W. 1994. “IMAX: A Gold Standard?” Business Week, March 7, p. 76.

Weil, S., and M. Pachter. 2002. Making Museums Matter. Washington, DC: Smithsonian Institute Press. 